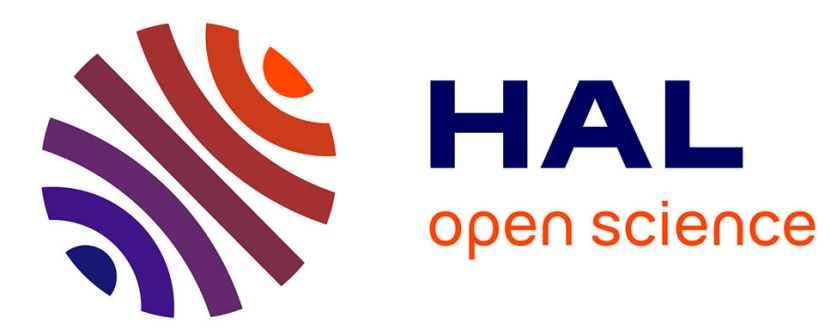

\title{
DIE WIRTSCHAFTLICHE BEDEUTUNG DER GRÖSSE IN DER MILCH- UND RINDFLEISCHPRODUKTION INNERHALB EINER RASSE
}

H. O. Gravert, K. Rohr

\section{- To cite this version:}

H. O. Gravert, K. Rohr. DIE WIRTSCHAFTLICHE BEDEUTUNG DER GRÖSSE IN DER MILCHUND RINDFLEISCHPRODUKTION INNERHALB EINER RASSE. Annales de génétique et de sélection animale, 1971, 3 (1), pp.106-106. hal-00892432

\section{HAL Id: hal-00892432 \\ https://hal.science/hal-00892432}

Submitted on 1 Jan 1971

HAL is a multi-disciplinary open access archive for the deposit and dissemination of scientific research documents, whether they are published or not. The documents may come from teaching and research institutions in France or abroad, or from public or private research centers.
L'archive ouverte pluridisciplinaire HAL, est destinée au dépôt et à la diffusion de documents scientifiques de niveau recherche, publiés ou non, émanant des établissements d'enseignement et de recherche français ou étrangers, des laboratoires publics ou privés. 
Up to date the protein polymorphism of the genital tract fluids remains theoretically unexplained. It has been proved in bulls, rams, boars, and cocks.

In the genital tract fluids of males and females there is a numher of the other physiologically very important substances the chemical composition and genetic control of which are still unknown. E. g. spermatozoa coating antigens in the seminal plasma of males, antiagglutinin, decapacitation and haemolytic factors, the factor sensitizing ampullar spermatozoa to cold shock, etc.

\title{
Effet du format sur l'efficacité des productions bovines
}

\section{Die wirtschaftliche Bedeutung deR Grösse in DeR Milch- Und RINDFLEISCHPRODUKTION INNERHALB EINER RASSY.}

\author{
H. O. GraverT und K. RoHR. - Bundesanstal für Milchforschung, \\ Kiel, BRD.
}

Wenn in einer Population eine positive genetische Korrelation zwischen Körpergrösse und Milchleistung besteht, kann bei einer Selektion auf Grösse ein indirekter Selektionserfolg in der Milchleistung erwartet werden. Dieser wird auf $42 \mathrm{~kg}$ berechnet, wenn die Widerristhöhe um $1,4 \mathrm{~cm}$ ansteigt. In vergleichenden Untersuchungen mit Holstein-Friesians und Deutschen Schwarzbunten betrug die Differenz in der Widerristhöhe $12 \mathrm{~cm}$ und in der metabolischen Körpergrösse $10 \%$. Um die gleiche Futterverwertung in der Milchproduktion (Erhaltungs- + Leistungsfutter) zu erzielen, waren für Holstein-Frisians $479 \mathrm{~kg}$ mehr Milch pro Jahr als für Deutsche Schwarzbunte erforderlich Daher ist eine Selektion in Richtung grösserer Kühe zur indirekten Verbesserung der Milchleistung ökonomisch sinnlos. - In der Fleischproduktion bestand zwischen Widerristhöhe und täglicher Zunahme eine geringe positive Korrelation, zwischen Widerristhöhe und Schlachtwert eine geringe negative Korrelation. Hieraus ergab sich, dass zwischen Widerristhöhe und dem ökonomischen Nutzen (Erlös minus Futterkosten) keine Korrelation bestand.

\section{GENETISCHE BEZIEHUNGEN ZWISCHEN MASTEIGENSCHAFTEN UND KÖRPERMASSEN VON MIICHMASTKÄLBERN UND OCHSEN}

\author{
F. Pirchner, G. Mayrhofer, H. Rohrbacher Ch. Rittmannsperger und \\ S. Chakrabarti. - Institut für Tierzucht, Tievärztliche Hochschule, Wien, \\ osterreich.
}

In Österreich werden drei Arten von Mastrindern erzeugt. Milchmastkälher (3-4 Monate), Jungmaststiere (12-18 Monate) und Mastochsen (2-4 Jahre). Nachdem sich diese Viehgattungen in vieler Hinsicht unterscheiden, ergibt sich die Frage nach der Existenz von GenotypUmweltinteraktionen. Zur Untersuchung dieses Problems werden 27 fraternale männliche Zwillingspaare der Braunviehrasse angekauft. Je ein Dsittel der Tierre wird, bzw. wurde als Milchmastkalb bis 14 Wochen Alter (mit Vollmilchersatz), je ein Drittel als Jungstiere bis 1 Jahr und der Rest als Ochsen bis $21 / 4$ Jahre gefüttert. Die Bedeutung der Interaktion Genotyp $\times$ Mastmethode ergibt sich aus dem Vergleich der Korrelation zwischen uniform gemästeten Paaren mit der Korrelation zwischen Paarpartnern, wo jeder Zwilling in einer 